\title{
Zastosowanie prędkości interwałowych PPS do modelowania ośrodka geologicznego
}

\begin{abstract}
Przedmiotem niniejszego artykułu jest prezentacja modelowania strukturalnego ośrodka geologicznego w domenie głębokości przy wykorzystaniu prędkości fal podłużnych pochodzących z azymutalnych pomiarów pionowego profilowania sejsmicznego PPS. W publikacji zostały przedstawione wyniki modelowania pola prędkości na bazie rozkładu prędkości interwałowych, obliczonych na podstawie inwersji sejsmicznej na transformacjach PPS-WPG. Uzyskany model prędkości posłużył do wykonania transformacji czas-głębokość sekcji sejsmicznych i obliczenia map strukturalnych. Przedmiotowa tematyka była podyktowana możliwością szerszego wykorzystania pomiarów PPS w polskim przemyśle naftowym i zwiększenia szczegółowości rozpoznania ośrodka geologicznego (w stosunku do sejsmiki powierzchniowej), co może w istotnym stopniu rzutować na efektywność poszukiwań i eksploatacji węglowodorów oraz na dokładność wierceń otworów poziomych lub kierunkowych.
\end{abstract}

Słowa kluczowe: PPS, transformacja PPS-WPG, inwersja sejsmiczna, modelowanie strukturalne.

\section{Application of VSP interval velocity to the modeling of geological medium}

This article presents results of modeling structural geological medium in depth domain, by using the velocity longitudinal waves, originating from azimuthal Vertical Seismic Profiling (VSP) measurements. The paper presents results of interval velocity modeling based on velocity distribution, calculated from seismic inversion on VSP-CDP transformations. The obtained velocity model was used to perform time-depth transformation of seismic sections and calculations of structural maps. The present topic was dictated by the possibility of wider useage of VSP measurements in the Polish Oil Industry, increasing the detail identification of geological medium (in relation to seismic surface), which may significantly affect the efficiency of exploration, exploitation of hydrocarbons and the accuracy of drilling horizontal or directional holes.

Key words: VSP, VSP-CDP transform, seismic inversion, structural modeling.

\section{Wstęp}

Użycie w badaniach sejsmicznych technologii pomiarów PPS 3C typu wieloazymutalnego daje unikalną możliwość kierunkowej oceny parametrów sprężystych na transformacjach PPS-WPG. Zastosowanie inwersji sejsmicznej, obliczanej metodą deterministyczną lub probabilistyczną (stochastyczną), na transformacjach PPS-WPG pozwala na uzyskanie rozkładu prędkości, który stanowi podstawę do szczegółowego śledzenia zmian parametrów fizycznych ośrodka geologicznego w strefie okołootworowej.

W krajowej literaturze w zakresie wykorzystania pomiarów PPS do modelowania strukturalnego ośrodka geologicznego autor opracowania nie znalazł żadnych rozwiązań ani przykładów, jakie zostały zaproponowane w niniejszym artykule. Spośród literatury obcojęzycznej pojawiła się publikacja w „Geophysical Prospecting” [11], w której autorzy Yingping Li i Ben Hewett wykorzystywali pomiary pionowego profilowania sejsmicznego do budowy i weryfikacji modelu prędkości w połączeniu z danymi sejsmicznymi w procesie przetwarzania sejsmicznego (pre i post-stack).

Prezentowana metodyka modelowania strukturalnego ośrodka geologicznego w domenie głębokości przy wykorzystaniu prędkości fal podłużnych pochodzących z azymutalnych pomiarów PPS stanowi nowe rozwiązanie wykorzystania sejsmicznych prędkości otworowych do budowania szczegółowego pola prędkości. 


\section{Metodyka badań PPS 3C}

Obszar badań i pomiarów geofizycznych, sejsmiki otworowej i powierzchniowej znajduje się w północnej części Polski. Na podstawie odwiertu W-1 określono profil litostratygraficzny, który reprezentowany jest przez utwory kambru, ordowiku, syluru, cechsztynu, triasu, jury, kredy oraz kenozoiku.

Jednym $\mathrm{z}$ istotnych celów badawczych powyższych prac było rozpoznanie budowy strukturalnej utworów syluru i ordowiku oraz wyznaczenie parametrów geomecha- nicznych skorelowanych z parametrami złożowymi gazu w pokładach łupków.

Azymutalne pomiary pionowego profilowania sejsmicznego PPS 3C zostały wykonane w otworze W-1 przez Zespół Sejsmiki Otworowej 1D/T Geofizyki Toruń w 2011 r. Źródłem wzbudzania był wibrator MARK III, o zakresie częstotliwości sweepu $8 \div 100 \mathrm{~Hz}$. W otworze $\mathrm{W}-1$ przeprowadzono cztery pomiary PPS $3 \mathrm{C}$ (rysunek 1 ): a)

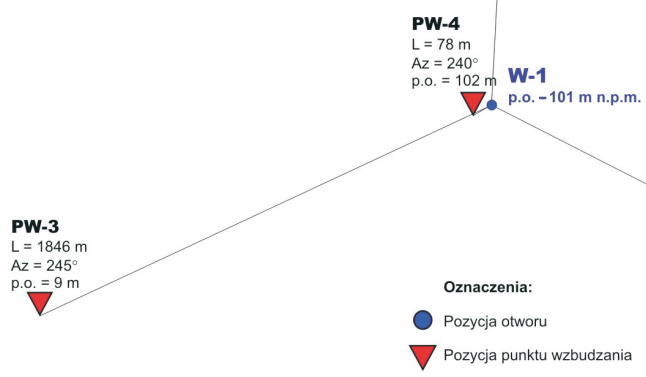

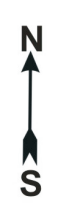

b)

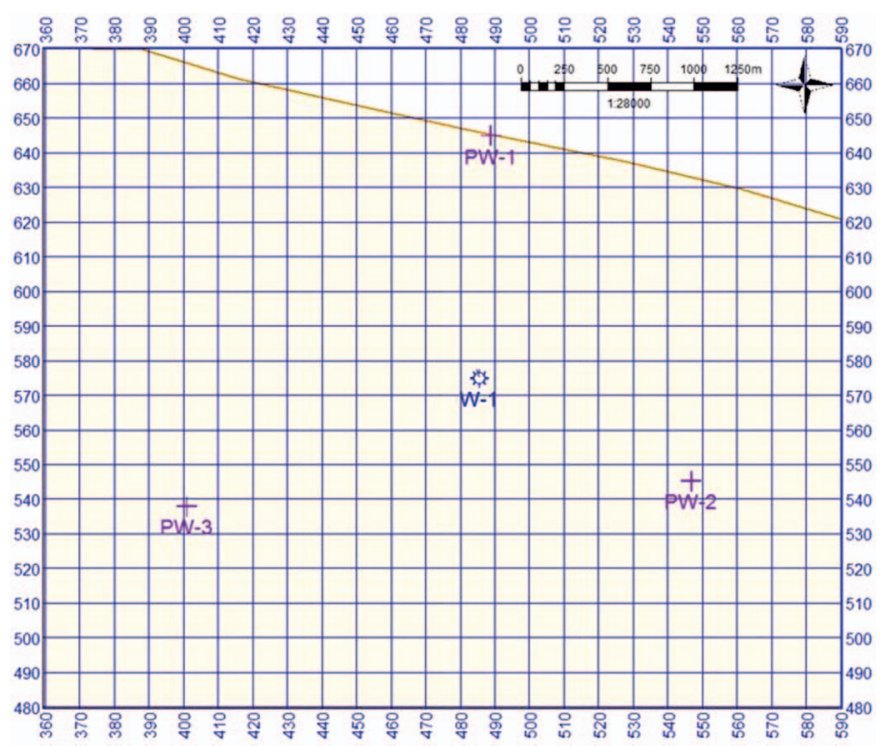

Rys. 1. a) Geometria rozmieszczenia punktów wzbudzań PPS 3C w otworze W-1;

b) rozmieszczenie punktów wzbudzań na tle zdjęcia sejsmicznego 3D

a)

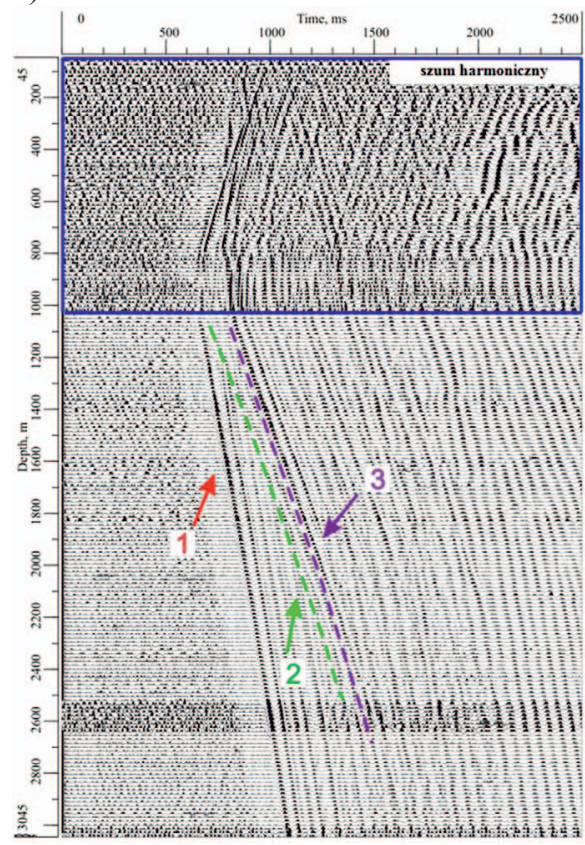

1 - fala padająca prosta, 2 - fala poprzeczna padająca, 3 - fala podłużna odbita b)

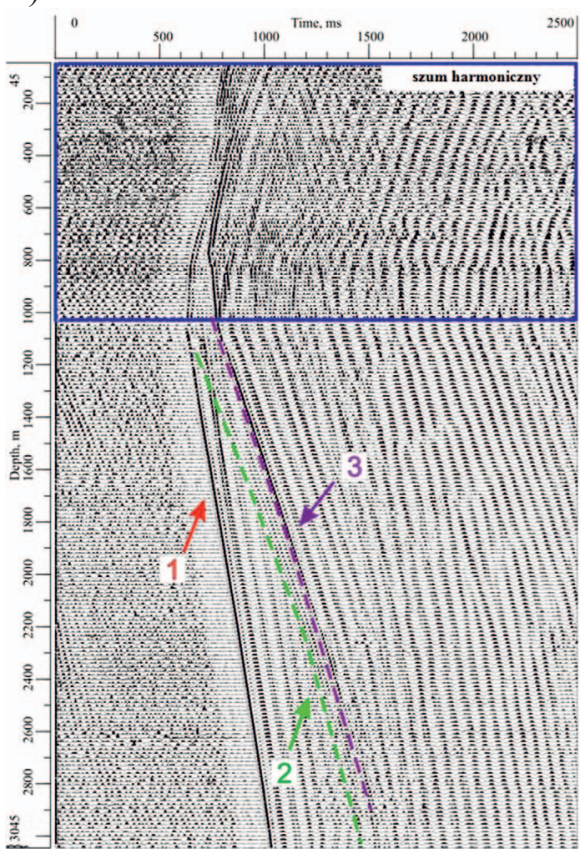

1 - fala padająca prosta, 2 - fala poprzeczna padająca, 3 - fala poprzeczna boczna c)

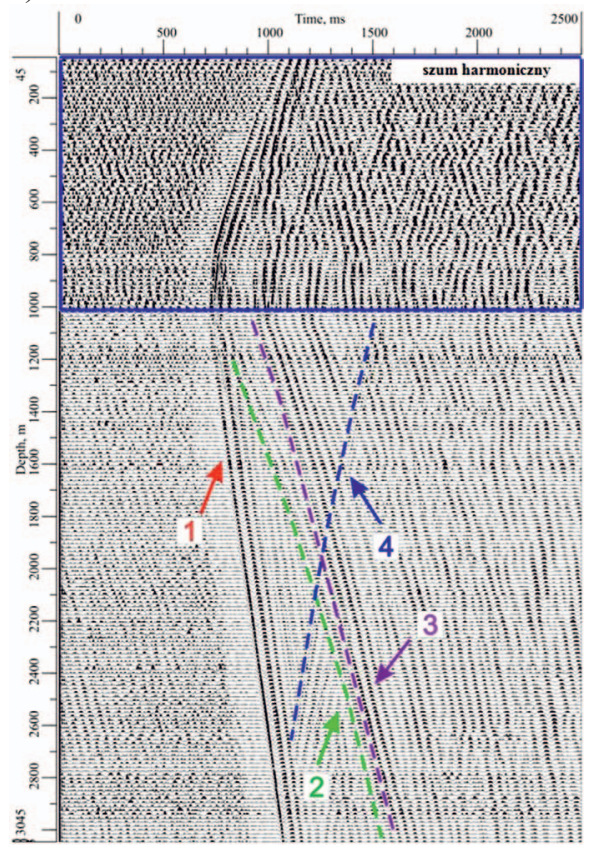

1 - fala padająca prosta, 2 - fala poprzeczna padająca, 3 - fala poprzeczna boczna, 4 - fala podłużna odbita

Rys. 2. Pola wejściowe PPS 3C - składowa pionowa $Z$, a) punkt wzbudzania PW-1, b) PW-2, c) PW-3 
- PW-1, PW-2 i PW-3 - punkty wzbudzania dla pomiarów offsetowych, mierzone w przedziale $45 \div 3045 \mathrm{~m}$, interwał pomiarowy $15 \mathrm{~m}$;

- PW-4 - punkt wzbudzania dla pomiaru zerooffsetowego, mierzony w przedziale $15 \div 3045 \mathrm{~m}$, interwał pomiarowy $15 \mathrm{~m}$.

Analizując dane wejściowe offsetowe PW-1-PW-3 składowej $Z$ PPS 3C, można zauważyć fale padające podłużne (proste), fale poprzeczne padające oraz boczne (rysunek 2). Ponadto na polu falowym PW-1 i PW-3 dodatkowo wyraźnie zaznacza się fala podłużna odbita.

Warto zaznaczyć, że na odległych rejestracjach offsetowych PW-1-PW-3, na głębokościach 45־1035 m, występuje intensywny harmoniczny szum, który wyraźnie osłabił rejestrację fal użytecznych oraz możliwość dokładnego określenia parametrów polaryzacji. $Z$ tej przyczyny przetwarzanie danych oddalonych (PW-1-PW-3) zostało wykonane w interwale $1035 \div 3045 \mathrm{~m}$ (rysunek 2 ).
Przetwarzanie pomiarów wieloazymutalnych PPS 3C było wykonywane w systemie UNIVERS firmy Geovers Ltd. z Moskwy. Wykorzystywano procedury: filtracji minimalnofazowej i pasmowej, edycji częstotliwościowej tras sejsmicznych, modelowania prędkości, selekcji różnych typów fal i modeli, wprowadzenia poprawek kinematycznych oraz dekonwolucji. Zastosowanie powyższych procedur było niezbędne, aby uzyskać pola falowe fal podłużnych PP i poprzecznych PS, które zostały użyte do wyznaczenia transformacji PPS-WPG.

Wyniki zestawień transformacji PPS-WPG dla wszystkich punktów wzbudzań (PW-1, PW-2, PW-3) z krzywą profilowania akustycznego (PA) wskazują na dobre dopasowanie oraz zgodność zmian wartości prędkości PA z zapisami falowymi PPS-WPG. Można dostrzec dobrą korelację dla markerów stratygraficznych: Sb (mułowce wapniste), O (ordowik) i Cm2 (kambr środkowy) oraz poziomów zbiornikowych (Jantar, Sasino) na obniżeniach prędkościowych oraz amplitudowych transformacji PPS-WPG. a)

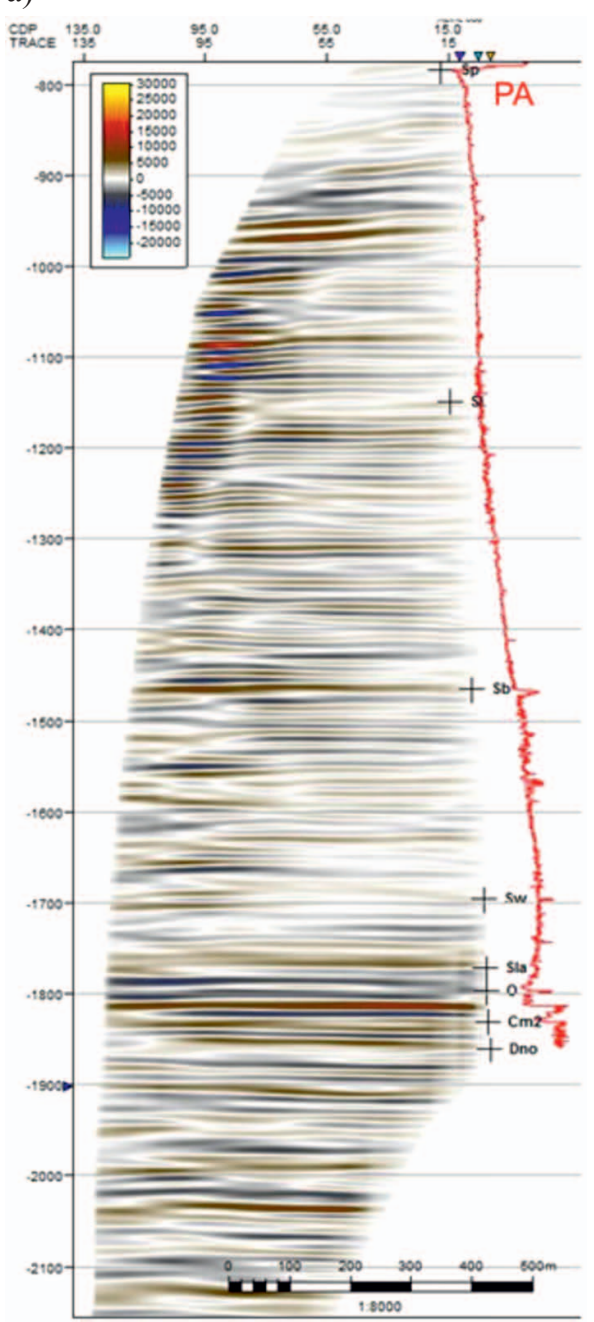

b)

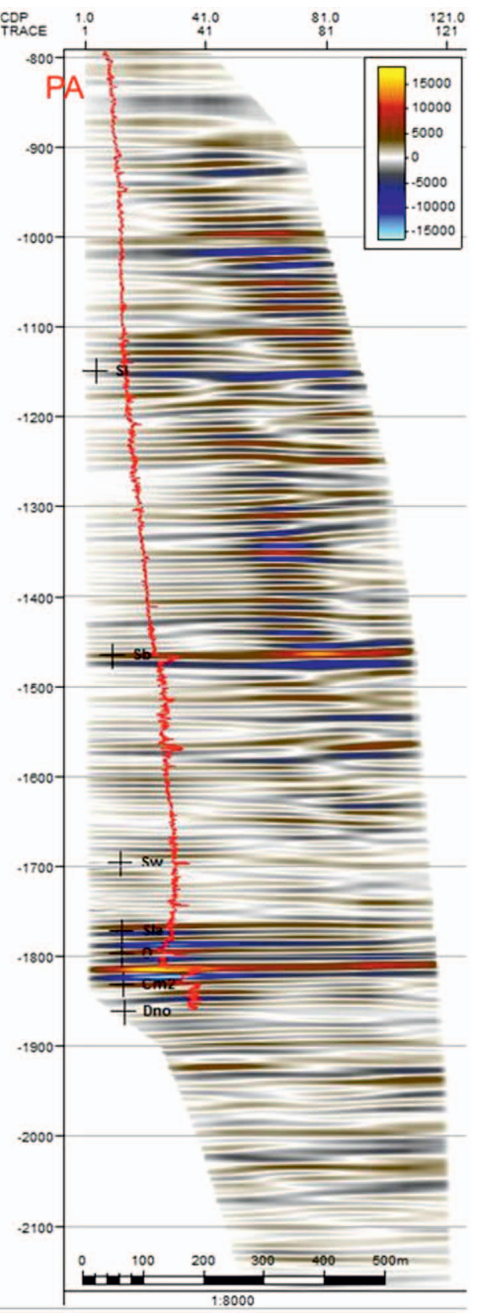

c)

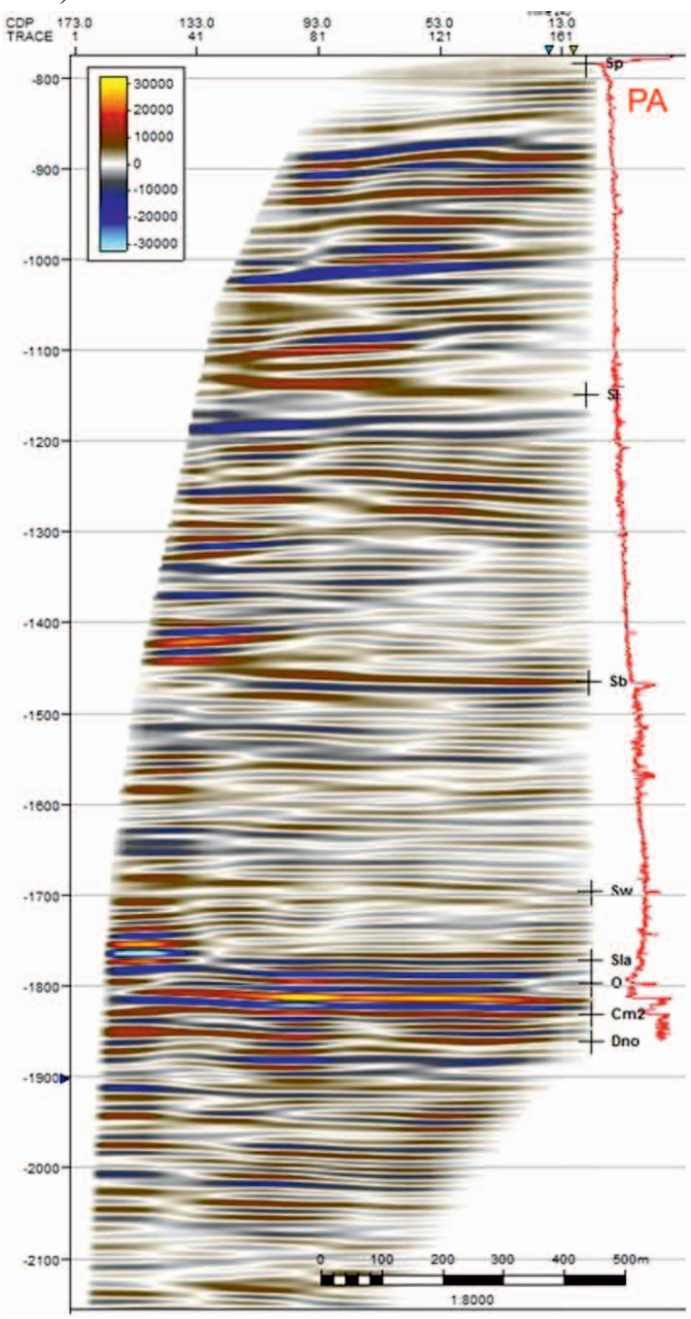

Rys. 3. Wynikowe pola falowe PPS-WPG dla punktów wzbudzań: a) PW-1, b) PW-2, c) PW-3 $\mathrm{z}$ dopasowaniem profilowania akustycznego PA 


\section{Obliczanie azymutalnych zmian prędkości na transformacjach PPS-WPG}

Obliczenie inwersji sejsmicznej w postaci impedancji akustycznej na offsetowych transformacjach PPS-WPG punktów wzbudzań PW-1, PW-2 i PW-3 dla fal podłużnych było wykonywane z wykorzystaniem autorskich programów dr K. Żukowskiej, które obecnie są własnością INiG - PIB. Zastosowana inwersja oparta jest na metodzie deterministycznej (inwersja rekursywna) [3].

Otrzymane wyniki inwersji sejsmicznej w postaci impedancji akustycznej umożliwiły uzyskanie rozkładu prędkości akustycznych wzdłuż azymutalnych punktów wzbudzań (rysunek 4). W przypadku punktów wzbudzań PW-3 oraz PW-2 fal podłużnych (rysunek 4b, c) w wynikach obliczonych prędkości akustycznych można zaobserwować znaczne zgrupowanie wysokich wartości prędkości na czasach poniżej $800 \mathrm{~ms}$ (PW-2 i PW-3), $1100 \mathrm{~ms}, 1400 \mathrm{~ms}$ i $1600 \mathrm{~ms}$ (PW-3). Powyższe wyniki wskazują na prawdopodobne błędy w obliczeniach, których nie można było zidentyfikować w ich trakcie. Prawdopodobnie jest to efekt procedury inwersji rekursywnej, która uśrednia widmo amplitudowe. Pozostałe wyniki obliczeń impedancji akustycznej charakteryzuje zadowalająca zmienność pozioma i pionowa.

Otrzymane rezultaty użycia inwersji sejsmicznej na transformacjach PPS-WPG wskazują, że metoda ta daje zadowalające wyniki do interpretacji litofacjalnej. a)

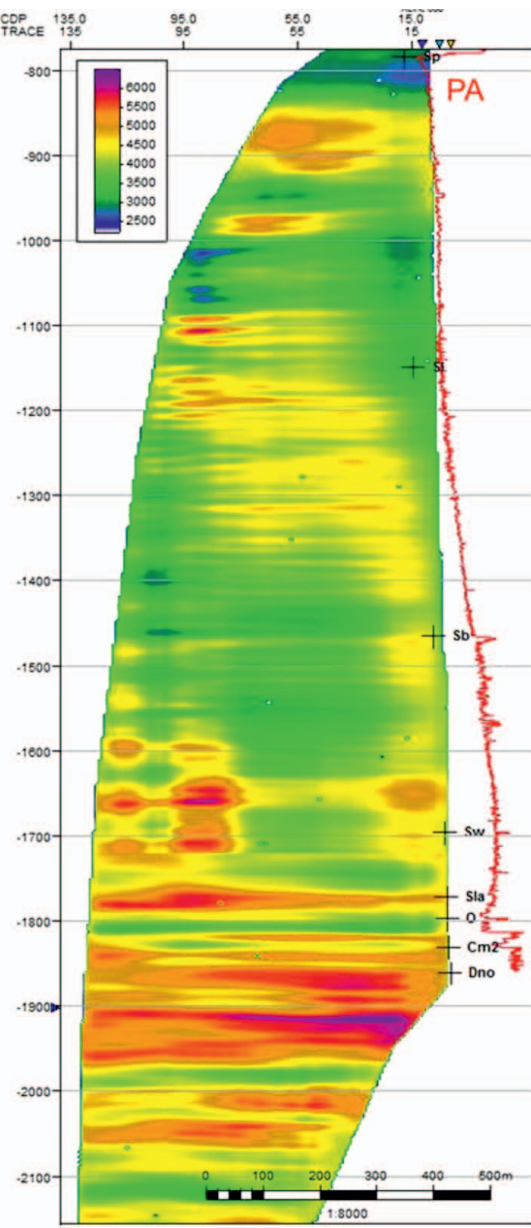

b)

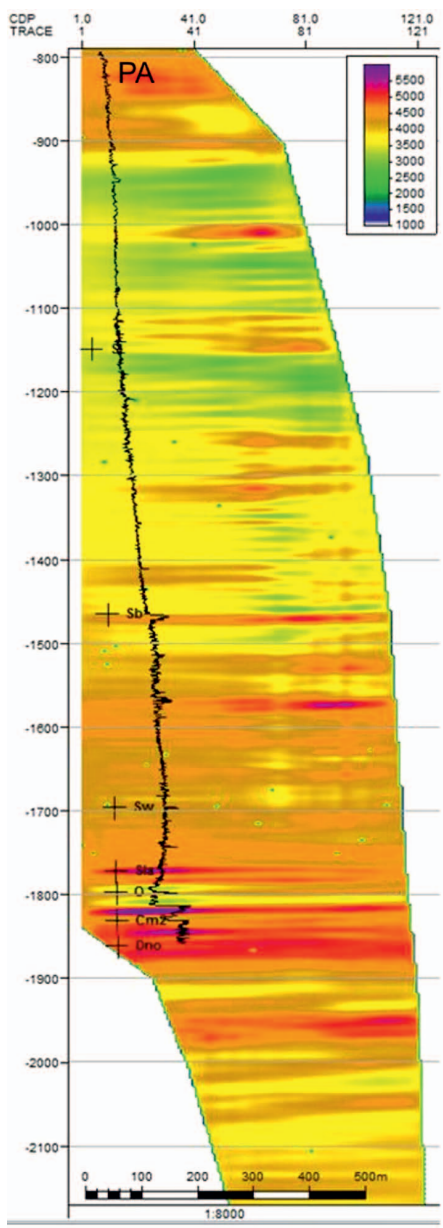

c)

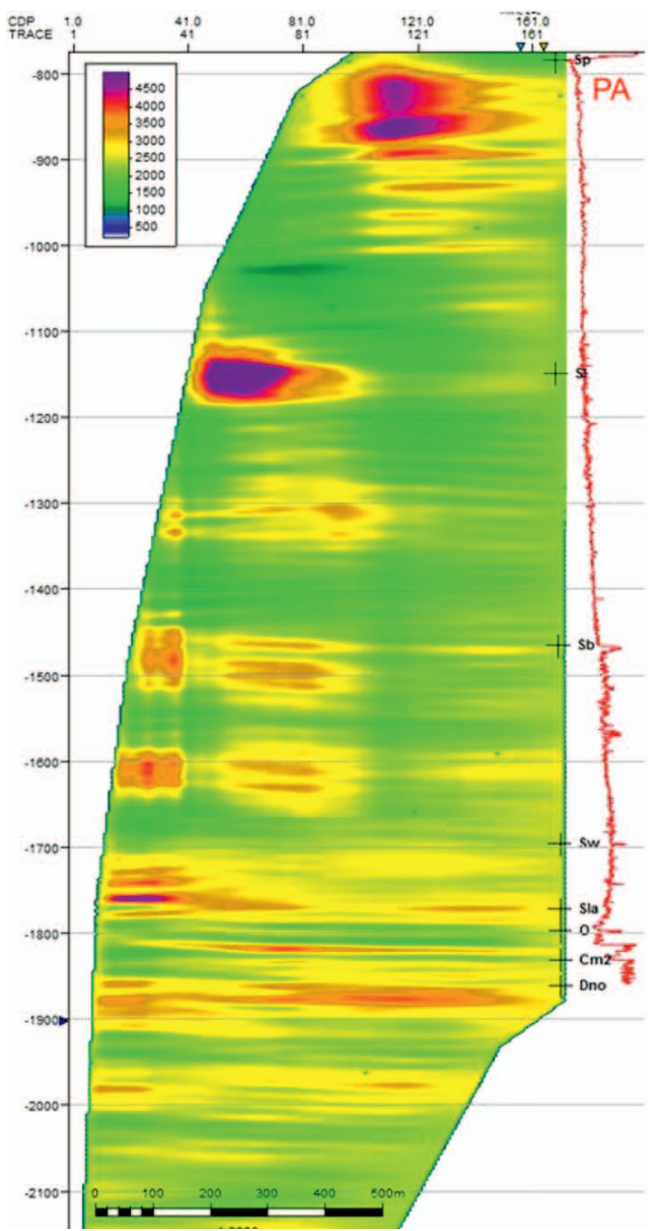

Rys. 4. Obliczone prędkości akustyczne na transformacjach PPS-WPG dla punktów wzbudzań: a) PW-1, b) PW-2, c) PW-3 $\mathrm{z}$ dopasowaniem profilowania akustycznego PA

\section{Model geologiczny w domenie czasu}

W celu dowiązania danych otworowych do horyzontów sejsmicznych został obliczony sejsmogram syntetyczny. Do jego obliczeń przyjęto wyekstrahowany elementarny sygnał sejsmiczny (wavelet) z dziesięciu tras i linii w bramce 1400 $\div 1848$ ms (długość okna 448 ms) usytuowanych wokół otworu W-1. Wyznaczony sygnał sejsmiczny został przetransformowany do sygnału zerofazowego w celu zachowania charakterystyki rzeczywistego pola falowego. Sejsmogram syntetyczny obliczono na podstawie profilowań otworowych, profilowania akustycznego oraz gęstości. 
Konstrukcja modelu prędkości została oparta na wykonanej interpretacji granic refleksyjnych, które były identyfikowane na podstawie korelacji sejsmogramu syntetycznego z zapisem sejsmicznym i otworowymi danymi stratygraficznymi w systemie Petrel. Interpretacja została przeprowadzona na fragmencie danych sejsmicznych 3D (rysunek 1b). Wyznaczono następujące granice: $\mathrm{Sb}, \mathrm{Sb}$ 1, Sla, Or, Or_V, Cm2, Cm2_1, Cm2_2, Pre (rysunek 5).

Wyznaczone horyzonty sejsmiczne: $\mathrm{Sb}, \mathrm{Sb} \_1$, Sla, Or, Or_V, Cm2, Cm2_1, Cm2_2, Pre na analizowanym fragmencie zdjęcia 3D ,przeniesiono" na dane PPS-WPG dla wszystkich offsetowych punktów wzbudzań: PW-1, PW-2, PW-3. Wykonana interpretacja na danych PPS-WPG stanowiła podstawę do obliczenia prędkości interwałowych,

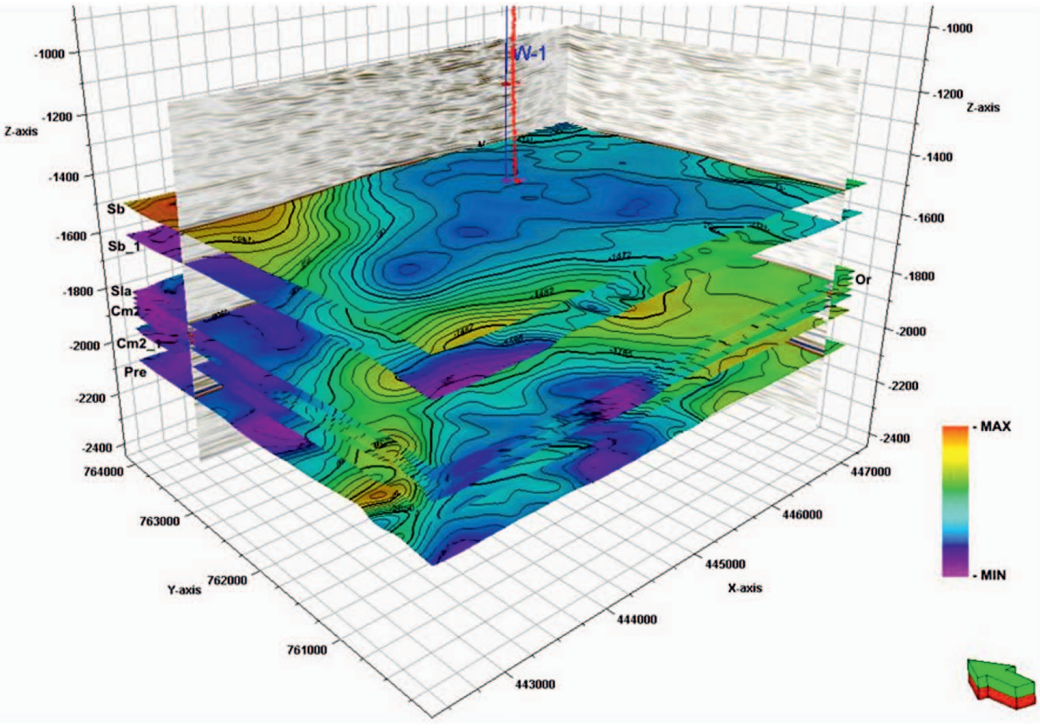

Rys. 5. Przestrzenna wizualizacja wyinterpretowanych horyzontów sejsmicznych w domenie czasu

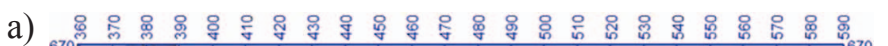

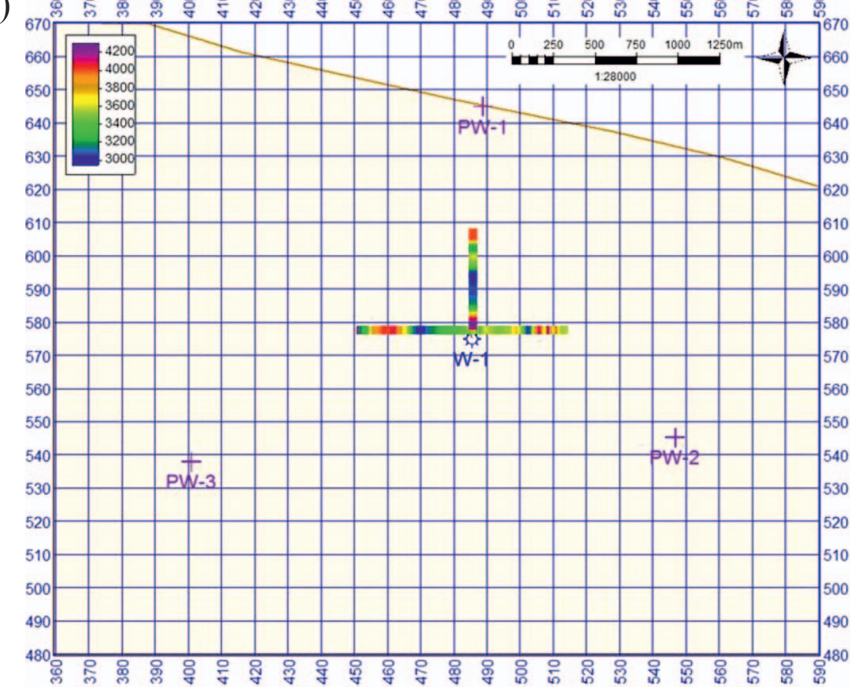

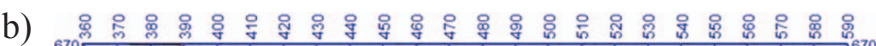

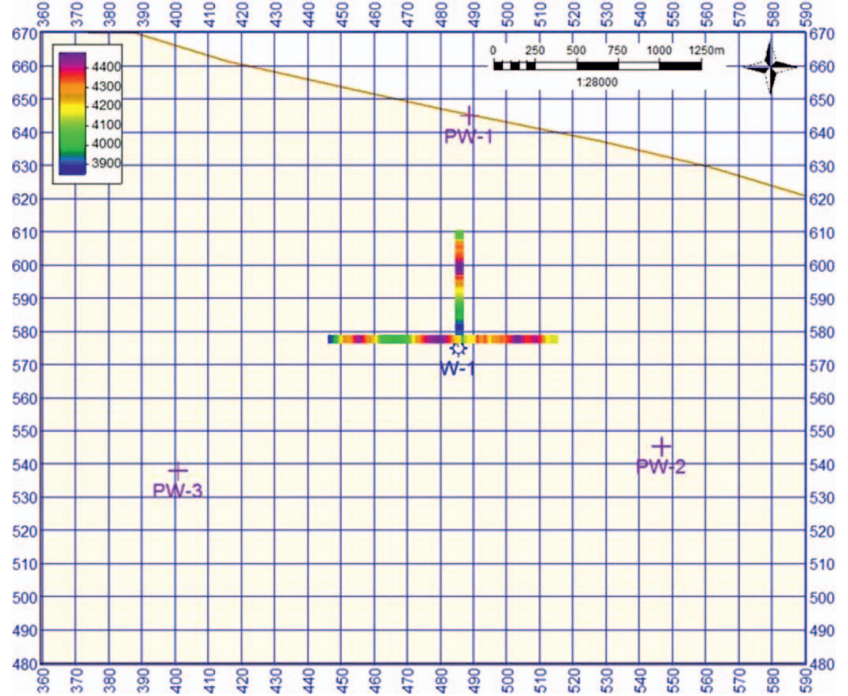

Rys. 6. Rozkłady prędkości interwałowych PPS-WPG w interwałach: a) Sb-Sb_1, b) Sla-Or - wzdłuż tras XL577 i IL484

wyznaczonych pomiędzy horyzontami: Sb-Sb_1, Sb_1-Sla, Sla-Or, Or-Or_V, Or_V-Cm2, Cm2-Cm2_1, Cm2_1Cm2_2, Cm2_2-Pre (rysunek 6).

Na podstawie rozkładu prędkości interwałowych obliczono mapy prędkości dla poszczególnych interwałów w analizowanym obszarze badań. Do konstrukcji map w rozpatrywanym obszarze sejsmicznym wykorzystano algorytm convergent interpolation. Algorytm ten pozwala na uzyskanie map o wysokiej rozdzielczości oraz szczegółowości. Dobrze sprawdza się w obliczeniach o małej ilości danych, zachowując ogólny trend morfologii. W przypadku gdy brak jest danych, algorytm pozwala na optymalną interpolację, z zachowaniem wysokiej dokładności rozkładu zmiennych. Mapy prędkości interwałowych zostały wygładzone w celu usunięcia anomalnych wartości prędkości (rysunek 7).
Do budowy modelu prędkości wykorzystano moduł Make velocity model systemu Petrel. Parametry wejściowe obliczanego modelu stanowiły mapy czasowe oraz mapy prędkości interwałowych PPS-WPG. Model dowiązany został do danych otworowych (markerów stratygraficznych). Modelowanie pola prędkości było wykonywane w zakresie granic $\mathrm{Sb}-\mathrm{Pre}$. Powyżej horyzontu Sb przyjęto prędkość $3000 \mathrm{~m} / \mathrm{s}$, a poniżej horyzontu Pre $-5000 \mathrm{~m} / \mathrm{s}$ w celu ustabilizowania modelu.

Ostateczny wynik obliczeń modelowania pola prędkości prezentuje rysunek 8 . W modelu uwidacznia się zmienność prędkości wywołana występowaniem anizotropii, potwierdzonej w pomiarach PPS. Obserwuje się znaczne obniżenie prędkości w przedziale granic Or_V-Cm2, co może być spowodowane zaleganiem formacji iłowców o obniżonej kompakcji, szczelinowatych, lub możliwym wpływem nasycenia węglowodorami serii złożowej. 
a)

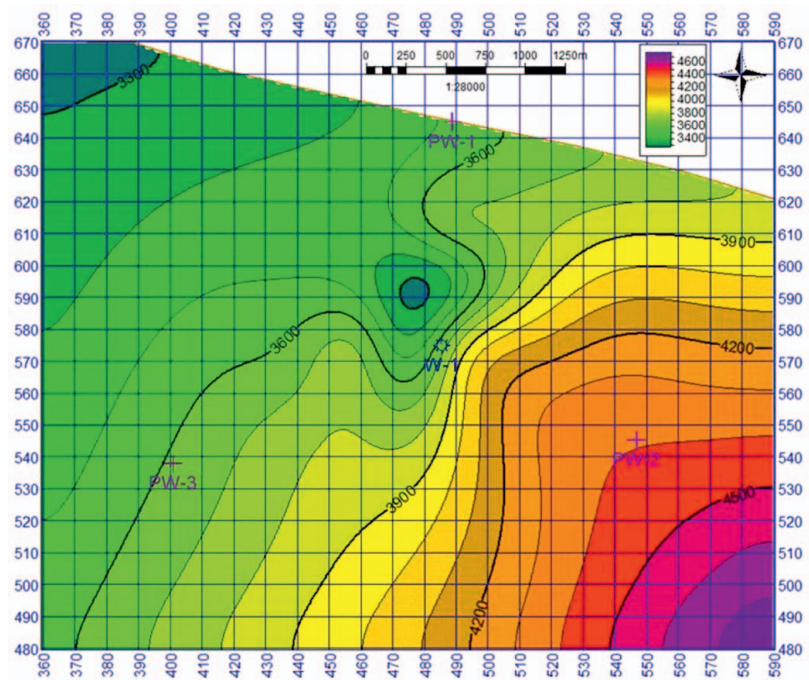

b)

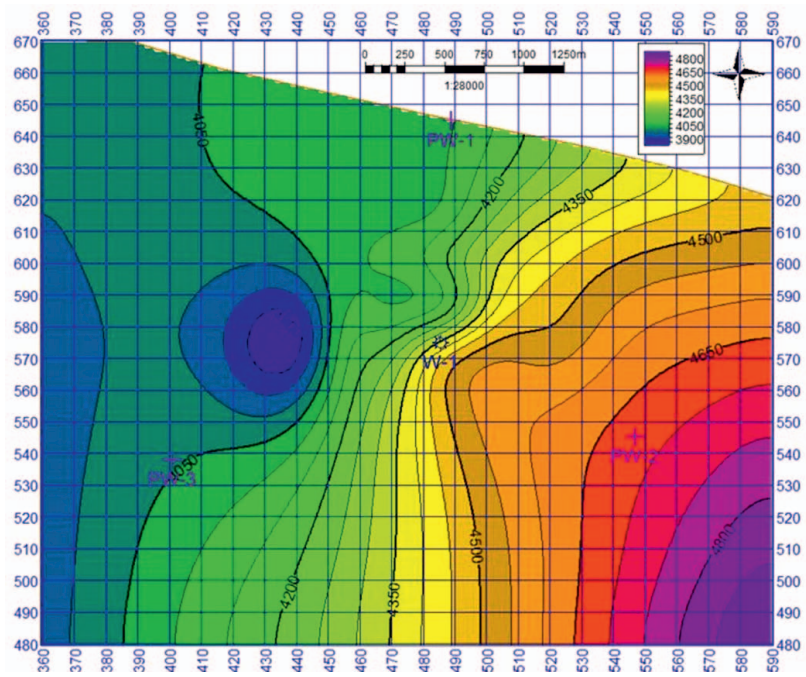

Rys. 7. Mapy rozkładu prędkości interwałowych PPS-WPG w interwałach: a) Sb-Sb_1, b) Sla-Or

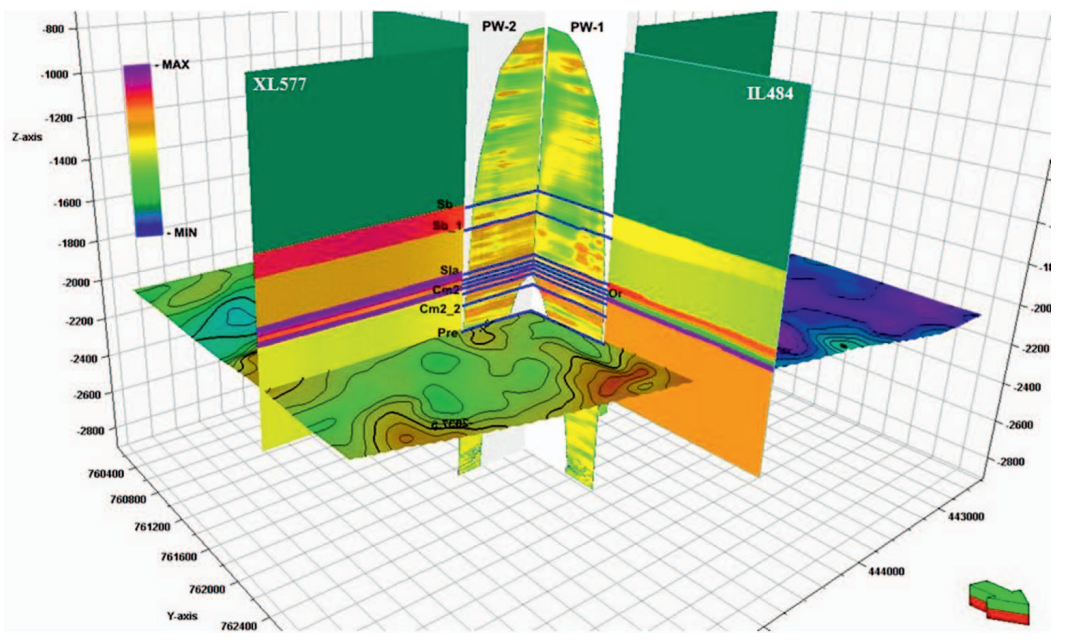

Rys. 8. Przestrzenna wizualizacja modelu prędkości w domenie czasu dla profili IL484

i XL577 z prędkościami akustycznymi transformacji PPS-WPG dla PW-1, PW-2 oraz mapą czasową Pre

\section{Model strukturalny w domenie głębokości}

Obliczony powyższy model pola prędkości posłużył do przeliczenia map czasowych na mapy strukturalne, w wyniku czego otrzymano głębokościowy model geologiczny w analizowanym obszarze badań, dowiązany do otworowych danych stratygraficznych (rysunek 9). Model ten posłużył również do przeliczenia danych sejsmicznych $3 \mathrm{D}$ z domeny czasu do domeny głębokości.

Na mapach strukturalnych, począwszy od horyzontu sejsmicznego Sla do Pre, uwidacznia się kierunek zapadania warstw z północno-zachodniego (NW) na południowo-wschodni (SE). Na mapie Sb kierunek zapadania jest odwrotny. Analizując wynikowe mapy głębokościowe pod kątem występowania obiektów strukturalnych (złożowych), można zauważyć, że na mapach Sla, Or, Or_V, Cm2, Cm2_2 i Pre pojawiają się dwa obiekty. Jeden z nich lokuje się na północny zachód, natomiast drugi na południowy zachód od otworu W-1 (rysunki 10a i 11a).

W celu zweryfikowania uzyskanych wyników w postaci map głębokościowych oraz sekcji sejsmicznych w dome- nie głębokości (IL484, XL577) posłużono się rezultatami przetwarzania danych sejsmicznych z aktualnymi opracowaniami badań przemysłowych. Wybrane zostały obliczone mapy głębokościowe horyzontów sejsmicznych Or oraz Cm2, które porównano z wynikami opracowania z 2013 r. (rysunki 10 i 11).

Na mapach horyzontu sejsmicznego Or można dostrzec odmienny kierunek zapadania warstw (rysunek 10): na obliczonej mapie jest nim NW-SE, natomiast na mapie pochodzącej z opracowania z 2013 r. - SE-NW (rysunek 10b). Na obu mapach wyraźnie widoczne są dwie struktury. Na obliczonej mapie jedna struktura, znajdująca się na północny zachód od otworu W-1, jest zamknięta izolinią 2790 m, natomiast druga znajduje się na południowy zachód od PW-3. Na porównawczej mapie (rysunek 10b) obie struktury są domknięte izolinią $2805 \mathrm{~m}$.

W przypadku horyzontu sejsmicznego $\mathrm{Cm} 2$ zapadanie warstw przebiega podobnie jak na mapach Or (rysunek 11). Na mapie obliczonej jest to NW-SE (rysunek 11a), natomiast 


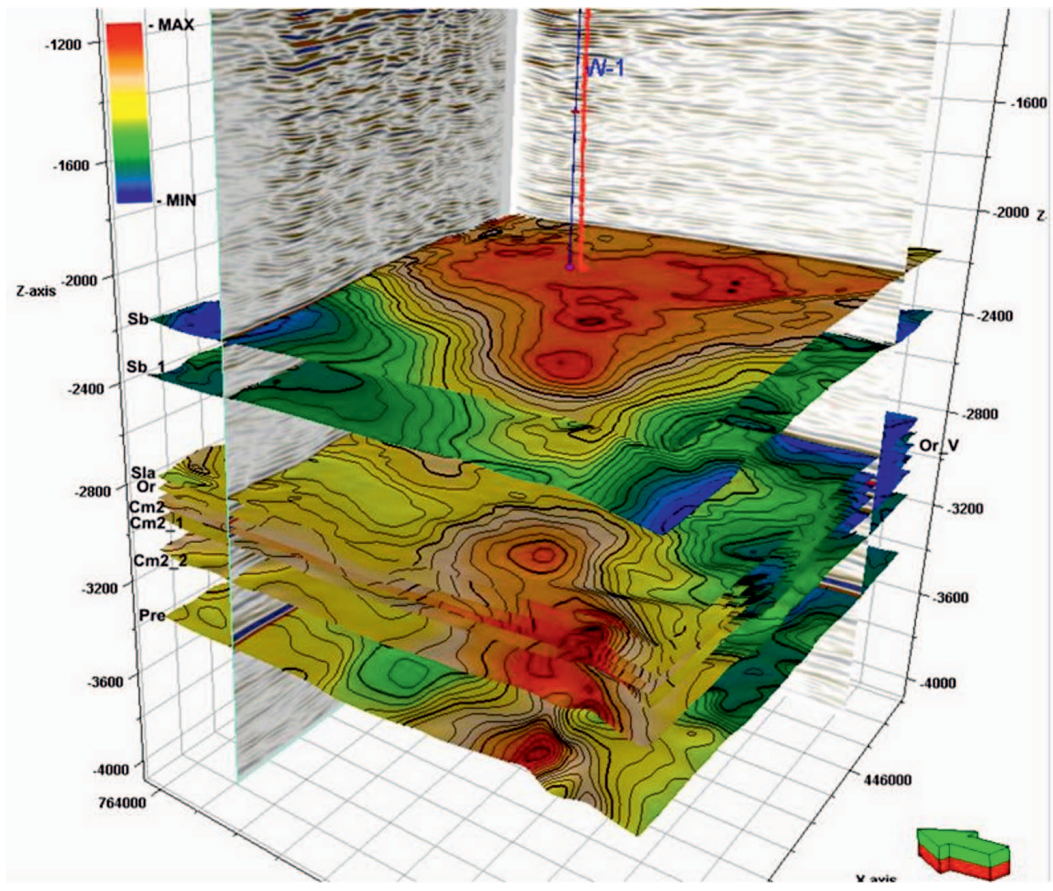

Rys. 9. Głębokościowy model geologiczny obszaru badań kierunek zapadania na mapie pochodzącej z opracowania z 2013 r. to SE-NW (rysunek 11b). Na obu mapach można dostrzec dwie struktury: jedna domknięta izolinią 2870 m (rysunek 11a), druga 2875 m (rysunek 11b), o różnym kształcie i umiejscowieniu względem otworu W-1.

Obliczony model strukturalny został również użyty do przeliczenia danych sejsmicznych z domeny czasu do domeny głębokości w celu zobrazowania zmian strukturalnych i facjalnych ośrodka geologicznego na analizowanym obszarze badań (rysunki 12b i 13b).

Na zapisie sejsmicznych głębokościowych profili IL484 oraz XL577 uzyskanych na podstawie transformacji czas-głębokość w oparciu o wyznaczony model prędkości z PPS - można wyraźnie dostrzec element strukturalny, widoczny w przedziale głębokościowym 2740 $\div 3050$ m (od horyzontu Sla do spodu otworu; rysunki 12b a)

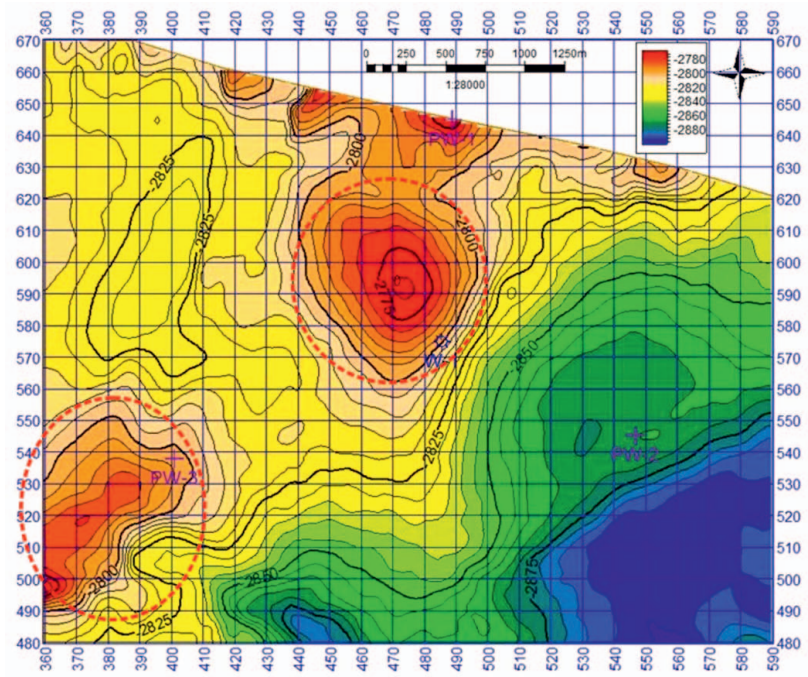

b)

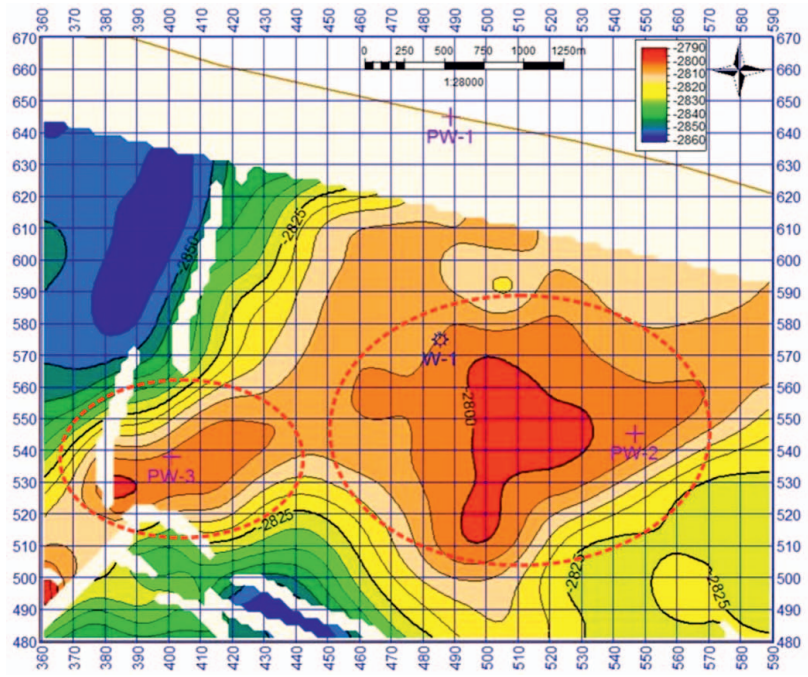

Rys. 10. Mapy głębokościowe horyzontu sejsmicznego Or: a) obliczona, b) według opracowania z 2013 r.

a)

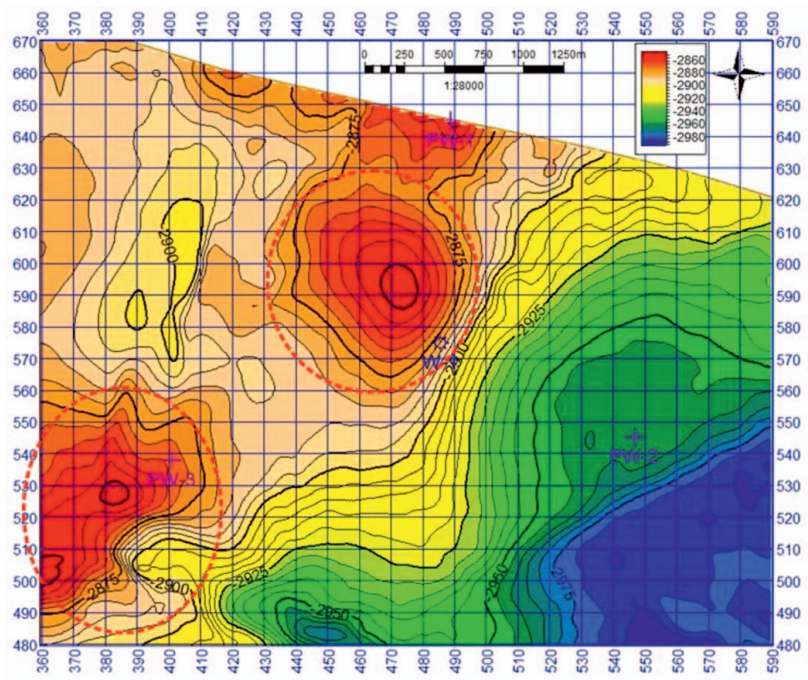

b)

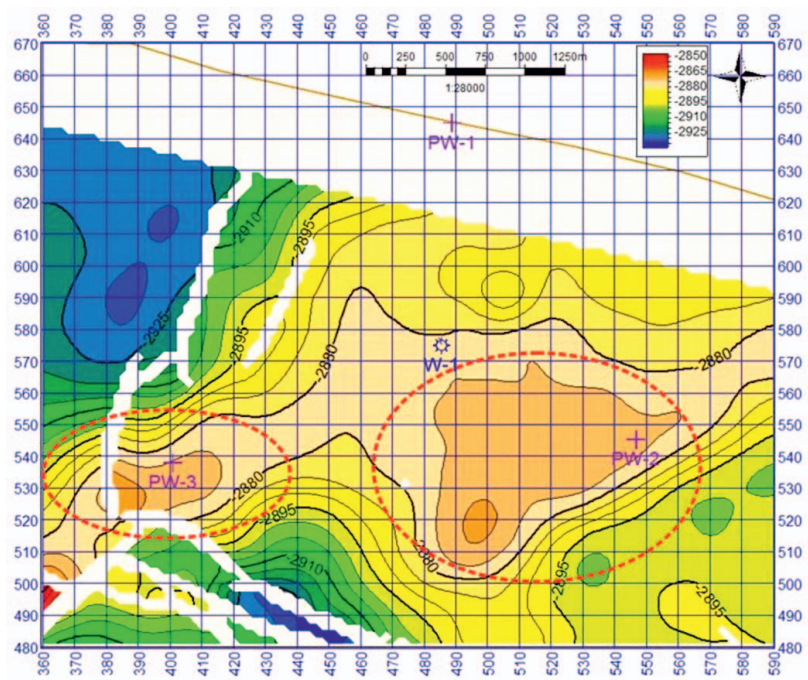

Rys. 11. Mapy głębokościowe horyzontu sejsmicznego Cm2: a) obliczona, b) według opracowania z 2013 r. 
i 13b). Na profilach pochodzących z opracowania z 2013 r. nie obserwuje się tej struktury (rysunki 12a i 13a).

Obliczone sekcje głębokościowe IL484 oraz XL577 po transformacji czas-głębokość zawierają podniesienie strukturalne. Biorąc pod uwagę specyfikę pomiarów pionowego profilowania sejsmicznego (PPS) oraz rezultat wyznaczenia modelu prędkości na ich podstawie, można wnioskować, że uzyskany wynik jest bardziej poprawny. Dodatkowo należy uwzględnić fakt, że analizowany otwór W-1 jest gazowy, co może przemawiać za poprawnością otrzymanych wyników. a)

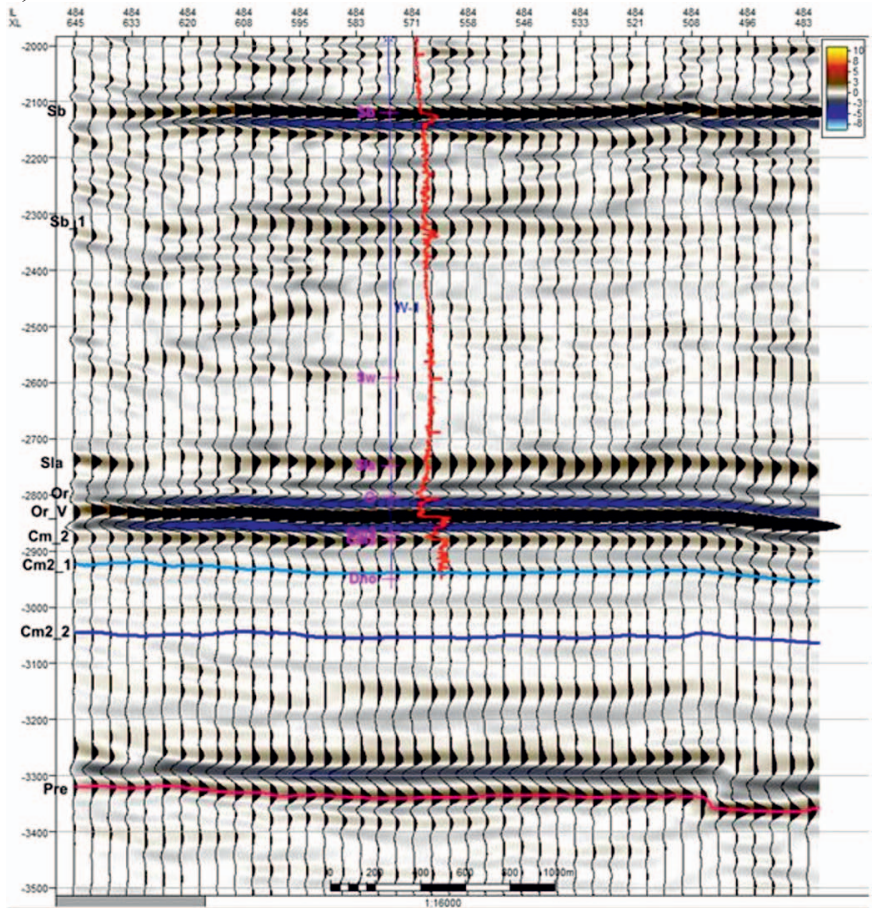

b)

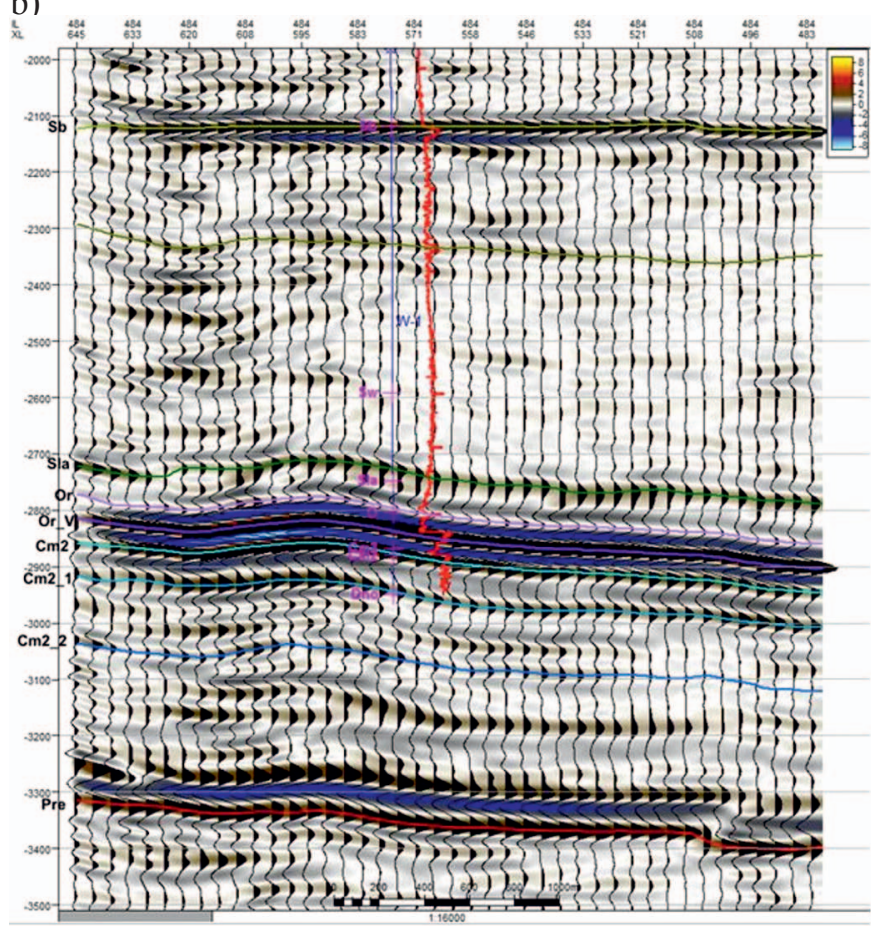

Rys. 12. Porównanie: a) głębokościowej sekcji sejsmicznej IL484 uzyskanej z opracowania z 2013 r. z b) sekcją po transformacji czas-głębokość w oparciu o obliczony model prędkości

a)

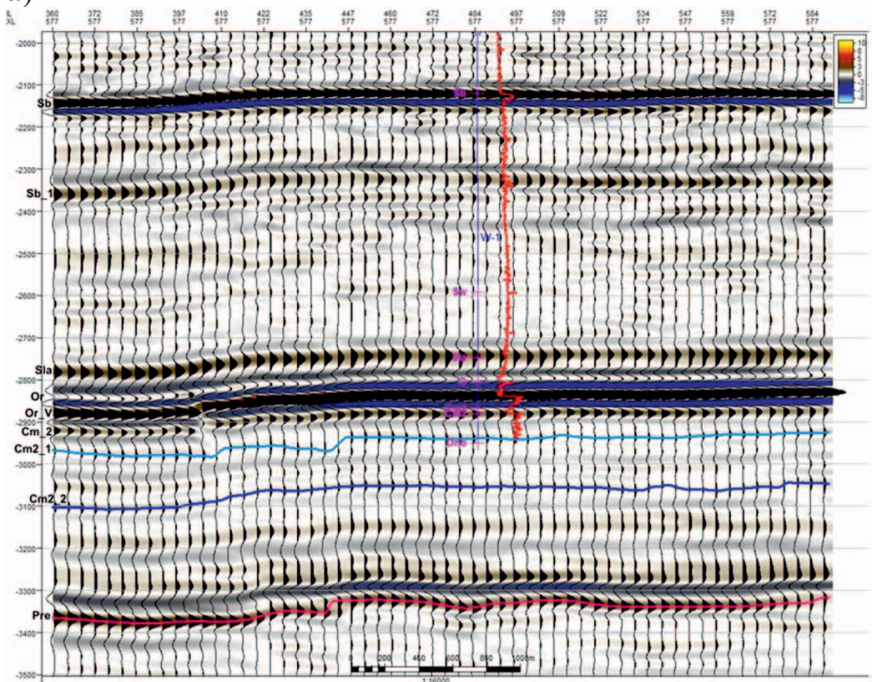

b)

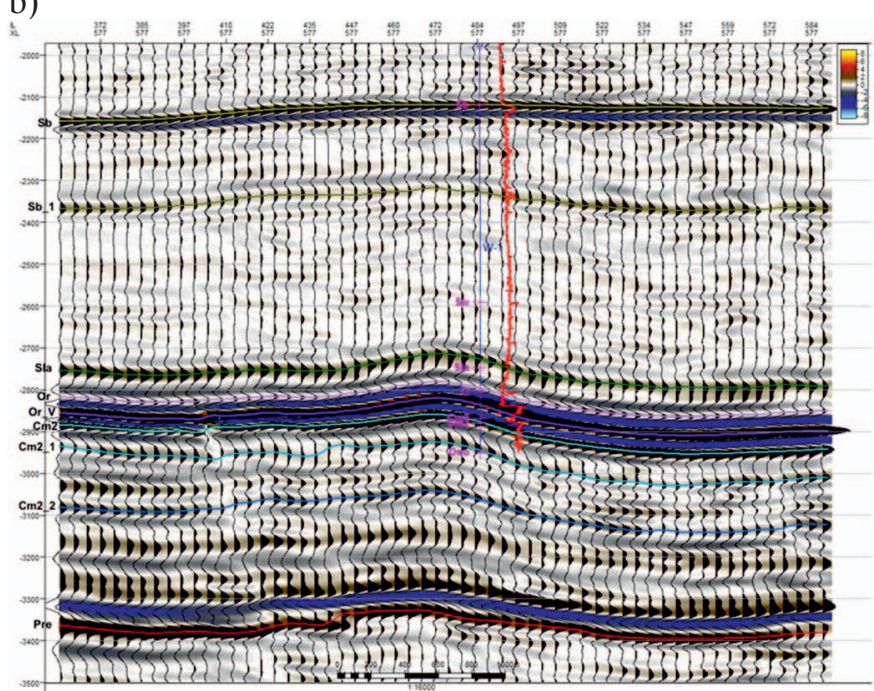

Rys. 13. Porównanie: a) głębokościowej sekcji sejsmicznej XL577 uzyskanej z opracowania z 2013 r. z b) sekcją po transformacji czas-głębokość w oparciu o obliczony model prędkości

\section{Podsumowanie i wnioski}

Na podstawie obliczonego modelu prędkości uzyskano obraz strukturalny odmienny i bardziej szczegółowy w stosunku do wyników z istniejących opracowań. Na głęboko- ściowych sekcjach sejsmicznych oraz mapach strukturalnych Or i Cm2 uwidacznia się obiekt strukturalny na północny wschód od otworu W-1, którego nie udokumentowano 
w dotychczasowych opracowaniach. Otrzymane mapy głębokościowe dostarczają więcej szczegółów strukturalnych oraz litofacjalnych, będąc cennym źródłem w analizach geologiczno-złożowych.

W celu sprawdzenia poprawności uzyskanych wyników strukturalnych, a szczególnie w odniesieniu do wykartowanego nowego elementu strukturalnego, należy zweryfikować model prędkości, wykonując obliczenia np. przy użyciu inwersji stochastycznej, albo (najlepiej równolegle) zastosować metodykę prestack depth migration na danych sejsmicznych.

Pole prędkości zastosowane w prezentowanym artykule, obliczone na podstawie pomiarów PPS, można rozszerzyć poza obszar akwizycji (PPS) wówczas, gdy warunki geologiczne są takie same jak w miejscu ośrodka geologicznego spenetrowanym przez otwór wiertniczy. To warunkuje zakres modelowanego pola prędkości. W przypadku modelowania pola prędkości w obszarze dużej zmienności geologicznej należy dysponować większą liczbą otworowych azymutalnych pomiarów rozmieszczonych $\mathrm{w}$ obrębie prac badawczych.

Jakość rezultatów otrzymanych dzięki zastosowanej metodyce obliczania modelu prędkości fal podłużnych do modelowania strukturalnego daje podstawę do jej wdrożenia w przyszłych pracach poszukiwawczych w polskim górnictwie naftowym.

Prosimy cytować jako: Nafta-Gaz 2016, nr 3, s. 155-163, DOI: 10.18668/NG.2016.03.01

Artykuł nadesłano do Redakcji 9.11.2015 r. Zatwierdzono do druku 10.02.2016 r.

Artykuł powstał na podstawie pracy INiG - PIB na zlecenie MNiSW pt.: Wykorzystanie prędkości interwałowych PPS do modelowania ośrodka geologicznego oraz identyfikacji zmian facjalnych - nr archiwalny: SR-4101-0057/15 oraz badań zrealizowanych w ramach projektu pt. Metodologia wyznaczania sweet spotów na podstawie własności geochemicznych, petrofizycznych, geomechanicznych $w$ oparciu o korelację wyników badań laboratoryjnych z pomiarami geofizycznymi i model generacyjny 3D, dofinansowanego przez Narodowe Centrum Badań i Rozwoju w ramach programu Blue Gas - Polski Gaz Łupkowy. Nr umowy: BG1/MWSSSG/13

\section{Literatura}

[1] Al-Chalabi M.: Seismic velocites - a critique. First Break 1994, vol. 12, no. 12, s. 589-596.

[2] Al-Chalabi M., Rosenkranz P. L.: Velocity-depth and timedepth relationships for a decompacted uplifted unit. Geophysical Prospecting 2002, vol. 50, no. 6, s. 661-664.

[3] Bartoń R.: Obliczanie inwersji sejsmicznej na azymutalnych transformacjach PPS-WPG fal podtużnych i poprzecznych. Nafta-Gaz 2015, nr 10, s. 711-719.

[4] Bartoń R.: Role of VSP measurement in investigation of anisotropy of geological medium. Galperin Readings - 2011, Moscow CGE 24-28 October 2011.

[5] Bartoń R.: Wyznaczanie kierunkowych zmian prędkości fal poprzecznych w strefie okolootworowej na podstawie azymutalnych pomiarów PPS 3C. Nafta-Gaz 2014, nr 8, s. 483-492.

[6] Gomez G., Planchart C., Chon Y., Di Massimo A., Gonzalez G., Sifontes E., Octavio D.: How integration of well log, core, borehole seismic and cross-well seismic data can offer a powerful tool in complex structural situations. First Break 2002, vol. 20, no. 6, s. 404-410.

[7] Gunning J., Glinsky M. E.: Detection of reservoir quality using Bayesian seismic inversion. Geophysics 2007, vol. 72 , no. 3, s. R37-R49.

[8] Helland-Hansen D., Magnus I., Edvardsen A., Hansen E.: Seismic Inversion for Reservoir Characterization and Well Planning in the Snorre Field. The Leading Edge 1997, vol.16, s. $269-274$
[9] Jędrzejowska-Tyczkowska H., Bartoń R.: Współczesne możliwości metody sejsmicznej w zadaniach ilościowej charakterystyki obiektów złożowych. Nafta-Gaz 2005, nr 7-8, s. 349-356.

[10] Jędrzejowska-Zwinczak H.: Inwersja sejsmiczna akustyczna i elastyczna fal podtuznych, konwertowanych i poprzecznych $w$ zagadnieniach interpretacji złożowej. Prace Naukowe INiG 2009, nr 160.

[11] Li Y., Hewett B.: Borehole seismic quantitative diagnosis of a seismic velocity model for $3 D$ seismic imaging of subsurface structures. Geophysical Prospecting 2014, vol. 62, no. 4, s. 719-739.

[12] Walia R., Brandt K., Duthie R., Whittaker R., Malterre E., Bell P.: New concepts for borehole and VSP data integration in seismic data processing. First Break 2005, vol. 23, no. 6, s. $83-87$.

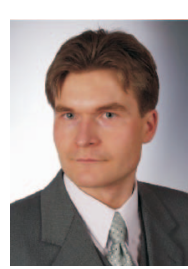

Dr inż. Robert BARTOŃ

Adiunkt w Zakładzie Sejsmiki

Instytut Nafty i Gazu - Państwowy Instytut Badawczy ul. Lubicz 25 A

31-503 Kraków

E-mail: robert.barton@inig.pl 